\title{
O Direito Fundamental à Boa Administração: da Carta de Direitos Fundamentais da União Europeia às perspectivas de sua efetivação e controle nas ordens constitucionais de Portugal e Espanha - desenvolvimentos comparativos na realidade brasileira
}

\author{
The Fundamental Right to Good Administration: from the Charter of \\ Fundamental Rights of the European Union to the prospects of its effectiveness \\ and control in the constitutional orders of Portugal and Spain - comparative \\ developments in the brazilian reality
}

\author{
Clarissa Sampaio Silva ${ }^{1}$ \\ ${ }^{1}$ Universidade de Fortaleza (UNIFOR), Fortaleza, CE, Brasil
}

\begin{abstract}
Resumo: O reconhecimento de um direito fundamental à boa administração pela Carta de Direitos Fundamentais da União Europeia implicou a fixação de posições garantísticas mínimas dos cidadãos perante a Administração Pública, com influxos nos ordenamentos constitucionais de seus Estados membros. Encontram-se, nas Constituições portuguesa e espanhola, formas de concretização do referido direito, tanto nas vertentes subjetiva quanto objetiva. Igualmente, na ordem constitucional brasileira, podem ser identificadas posições subjetivas e elementos objetivos realizadores do direito à boa administração. Numa e noutra situação, as formas de seu controle são diferentes, os quais devem ser adaptados aos seus respectivos espectros.
\end{abstract}

Palavras-chave: Boa Administração. Direito Fundamental.
Abstract: The recognition of a fundamental right to good administration by the Charter of Fundamental Rights of the European Union implied the establishment of minimum guaranteed positions of the citizens before the Public Administration, with inflows in the constitutional laws of its Member States. In the Portuguese and Spanish constitutions are found ways of realizing this right in both subjective and objective terms. Likewise, in the Brazilian constitutional order, it is possible to identify subjective positions and objective elements that lead to the implementation of the right to good administration. In one or another situation, the forms of their control are different, which must be adapted to their respective spectra.

Keywords: Good Administration. Fundamental Right.

Recebido em: 21/11/2017

Revisado em: 04/10/2018

Aprovado em: 15/03/2019 


\section{Introdução}

A consagração, no artigo 41 da Carta de Direitos Fundamentais da União Europeia, de um direito à boa administração trouxe o debate sobre sua configuração e repercussão no âmbito do direito interno dos seus países membros.

Em virtude de tal reconhecimento colocam-se questões como o âmbito de vinculação de referido preceito, se apenas para os órgãos e entidades da União Europeia, ou para os Estados membros; a existência ou não, nos ordenamentos constitucionais internos, de um verdadeiro direito fundamental à boa administração ou se esse preceito deve ser compreendido como o objetivo mesmo do Estado, do qual decorreriam posições pontuais que o concretizam; a identificação de marcos constitucionais nos ordenamentos internos realizadores do direito à boa administração; o conteúdo do que se compreende como boa administração; a complementação da previsão contida no artigo 41 da Carta de Direitos Fundamentais pelo Código Europeu de Boas Condutas Administrativas e o valor jurídico que ele possui.

Para tanto, e como objetivo geral do presente artigo, partir-se-á da compreensão de tal tema nos termos da própria Carta de Direitos Fundamentais e no plano constitucional de Espanha e Portugal, além da abordagem doutrinária da matéria, agregadora de importantes percepções que lhes são complementares, ensejadoras, por sua vez, de formas de controle do direito à boa administração feitas pelo Poder Judiciário ou por outras instâncias.

Em seguida, e agora partindo para objetivos específicos, passa-se a realizar comparação com a ordem constitucional brasileira de modo a nela identificar elementos normativos que contenham o reconhecimento do direito à boa administração, nas dimensões objetiva e subjetiva.

Uma vez realizada tal análise, busca-se identificar, ainda a título de objetivos específicos, dentro da legislação e com recurso à doutrina e jurisprudência os meios de controle do direito à boa administração nas instâncias competentes, apontando suas potencialidades e limites, com vistas 
a utilizar tal conceito para valorizar e aprimorar práticas administrativas que sejam coetâneas com os valores e desideratos que dele emanam.

A presente análise, fundando-se em uma pesquisa de cunho bibliográfico e exploratório, pretende identificar contribuições do debate travado no âmbito da União Europeia para a realidade brasileira.

\section{Do artigo 41 da Carta de Direitos Fundamentais da União Eu- ropeia: histórico e conteúdo}

Com a proclamação, em 7 de dezembro de 2000, da Carta de Direitos Fundamentais da União Europeia, restou assegurado um catálogo de direitos, com caráter de fundamentalidade formal e material, e não apenas meramente declaratória, invocáveis perante os órgãos e instituições da União Europeia, consoante destaca Canotilho (2001, p. 14).

Veicula a Carta de Direitos Fundamentais normas para a União Europeia, e não para os seus Estados membros ${ }^{1}$, a não ser naquelas situações em que esteja em causa a aplicação do direito comunitário pelos órgãos estatais. Serve ainda a Carta como "[...] parâmetro de validade e critério de interpretação e aplicação de todo o direito comunitário [...]", além de desempenhar uma função política, qual seja, a de ensejar "[...] uma influência mútua na aplicação dos catálogos dos direitos fundamentais [...]", segundo destaca Vieira de Andrade (2001, p. 84-88).

Ou seja, além das situações em que os Estados-membros estejam a aplicar o direito comunitário, há de se reconhecer a ocorrência de impactos, nas ordens de cada Estado membro, dos direitos assegurados pela Carta, servindo mesmo para inspirar a evolução da proteção daqueles nos respectivos planos nacionais, assumindo aquela, assim, a função de uma soft law, nas palavras de Moura Ramos (2001, p. 55).

1 O artigo 51 da Carta de Direitos Fundamentais possui a seguinte redação: “As disposições da presente Carta têm por destinatários as Instituições e órgãos da União, na observância do princípio da subsidiariedade, bem como aos Estados-Membros, apenas quando apliquem o direito da União. Assim sendo, devem respeitar os direitos, observar os princípios e promover a sua aplicação, de acordo com as respectivas competências". 
No tocante ao Direito Administrativo e suas fontes, semelhante fenômeno representa uma "contaminação da normatividade interna pela ordem jurídica comunitária”, conferindo uma nova dimensão ao Direito Administrativo, com a consequente compreensão da Comunidade Europeia como uma "Comunidade de Direito Administrativo", segundo Otero (2003, p. 457).

Mirando para o texto da Carta de Direitos Fundamentais, no capítulo destinado aos direitos políticos dos cidadãos (artigos 39 a 46) $)^{2}$, os quais são dotados de aplicabilidade direta, sendo judiciáveis e ensejando, nomeadamente uma função reacional, de modo a ser possível identificar-lhes, também, aspectos objetivos, institucionais e de participação, de acordo com Weber (2002, p. 86).

Com efeito, a necessidade de assegurar, no âmbito da União Europeia, uma pauta mínima de posições que correspondam ao exercício civilizado e controlado do poder pelos seus órgãos e instituições levou o Comitê de Ministros do Conselho da Europa a expedir a Recomendação $\mathrm{R}$ (80) 2, em 11 de março de 1980, e que, aliada à jurisprudência do Tribunal de Justiça das Comunidades Europeias e do Tribunal de Primeira Instância, acarretou a formulação do direito à boa administração, constante do artigo 41 da Carta de Direitos Fundamentais da União Europeia, com a seguinte redação:

1. Toda pessoa tem direito a que as instituições e órgãos da União tratem de seus assuntos de forma imparcial e equitativa e dentro de um prazo razoável

\footnotetext{
${ }^{2}$ Entre os direitos assegurados no Capítulo V, estão: 1) o direito de eleger e ser eleito nas eleições para o Parlamento Europeu, bem como o direito de eleger e ser eleito para as eleições municipais (artigos 39 e 40); 2) o direito a uma boa administração (artigo 41); 3) o direito de acesso aos documentos do Parlamento Europeu, do Conselho e da Comissão (artigo 42); 4) o acesso a qualquer cidadão, ao Provedor de Justiça da União, no tocante a casos de má administração na atuação das Instituições ou órgãos comunitários (artigo 43); 5) direito de petição, por parte de qualquer cidadão, pessoa singular ou coletiva, ao Parlamento Europeu; 6) direito de livre circulação e permanência dos cidadãos nos territórios dos Estados-Membros (artigo 45); 7) direito à proteção diplomática e consular dos cidadãos da União em países terceiros em que seu Estado-membro não se encontre representado, nas mesmas condições que os nacionais desse Estado (artigo 46).
} 
2. Este direito inclui em particular:

- o direito de toda pessoa de ser ouvida antes que se tome contra ela uma medida individual que the afete desfavoravelmente

- o direito que toda pessoa a ter acesso a expediente que lhe afete, dentro do respeito aos interesses legítimos da confidencialidade e do segredo profissional e comercial

-a obrigação que incumbe à Administração de motivar suas decisões.

3. Toda pessoa tem direito à reparação pela Comunidade pelos danos causados por suas instituições ou seus agentes no exercício de suas funções, em conformidade com os princípios gerais comuns aos Direitos dos Estados membros.

4. Toda pessoa poderá dirigir-se às instituições da União em uma das línguas dos Tratados e deverá receber uma contestação na mesma língua.

Tais posições corresponderiam a um padrão mínimo de direitos que os cidadãos da União Europeia possuem perante seus órgãos e instituições, consolidando assim o entendimento jurisprudencial sobre o que se compreende como boa administração, embora seja possível observar nos ordenamentos internos, desdobramentos e posições que, ao fim e ao cabo, remetem a referido direito fundamental.

Em princípio, embora a Carta da União Europeia tenha como destinatários as instituições e órgãos da própria União Europeia, seu artigo 51 prevê sua aplicação aos Estados membros "quando apliquem o Direito da União”, a revelar, assim sua vocação expansiva, consoante observa Baquer (2011, p. 47).

A ideia de boa administração contrapõe-se, por sua vez, à de má administração, compreendida, num primeiro momento, consoante explica Rodriguez (2011, p. 139), de modo exemplificativo, abrangendo situações como irregularidades e omissões administrativas, abusos de poder, favoritismos, atrasos injustificados, ausência de informação vindo a receber, em 1998, mercê da aprovação, pelo Parlamento Europeu de uma Resolução, a seguinte definição: “[...] produz-se má administração quando um orga- 
nismo público não labora em conformidade com as normas e princípios aos quais deve obrigatoriamente ater-se".

Enquanto o conceito da boa administração é obtido mediante a enunciação de determinadas posições, plenamente exigíveis, o de má administração finda por apresentar indeterminação, compreendendo ele, na verdade, uma zona entre o que seria estritamente ilegal, cujo controle caberia ser feito pela via judicial e aquilo que, apesar de não vir a ser ilegal, não seria passível de ser sindicado pelo Poder Judiciário, demandando outra forma de controle, no caso, o realizado pelo Provedor de Justiça da União, mediante petição apresentada por "[...] qualquer cidadão da União, bem como qualquer pessoa singular ou coletiva com residência ou sede social num Estado-membro respeitantes a casos de má administração na atuação das Instituições ou órgãos comunitários, com exceção do Tribunal de Primeira Instancia no exercício das respectivas funções jurisdicionais [...]", nos termos do artigo $43^{\circ}$ da Carta.

Além da previsão do direito à boa administração, o Parlamento Europeu aprovou, em 6 de setembro de 2001, um Código de Boa Conduta Administrativa para as instituições e órgãos da União Europeia, cuidando das relações entre seus funcionários e os cidadãos, desenvolvendo os princípios da imparcialidade e da equidade, referidos pelo artigo 41 da Carta, e trazendo valores qualificados como fundamentais e que são: a legitimidade, a não discriminação, a proporcionalidade, a imparcialidade, a independência, a objetividade, profissionalismo e justiça, conforme observa Rodriguez (2011, p. 141).

Como medidas concretizadoras de tais valores, impõe o código a obrigação de remissão, por instituições europeias, ao serviço competente, das cartas e reclamações encaminhadas pelo cidadão, o qual será notificado do nome e telefone do funcionário encarregado, devendo as decisões ser adotadas no prazo de dois meses e, não sendo possível, necessita o interessado ser informado com a maior brevidade possível. Tem-se, também, a imposição de tratamento reservado dos dados pessoais dos cidadãos, com necessidade de respeito de sua integridade e vida privada.

Apesar de referido código não possuir força vinculativa, carecendo-lhe a aprovação de um Regulamento que reconheça seu conteúdo, de- 
sempenha o papel de soft law no ordenamento comunitário, podendo servir de paradigma para o estabelecimento de um código único, eliminando a existência de outros existentes em cada um dos órgãos e instituições da União Europeia, conforme pontua Rodriguez (2011, p. 143).

Em síntese, o direito fundamental à boa administração no âmbito dos órgãos e instituições da União Europeia abrange posições defensivas por parte dos cidadãos, compreendendo o direito a se manifestar, antes de qualquer medida ou decisão desfavorável que venha a lhe afetar, o direito ao acesso a expedientes e documentos que se encontrem em poder dos órgãos comunitários; o direito à reparação por danos causados por esses últimos, e por fim, o direito a dirigir-se aos órgãos da União Europeia na linguagem de seu Estado-membro.

As disposições, por sua vez, do Código de Boa Conduta reforçam a realização de tais posições, disciplinando, entre outros aspectos, a forma de relacionamento entre os cidadãos e os funcionários da União Europeia.

Por fim, para os casos de má administração, há a possibilidade de formulação de petição ao Provedor de Justiça, implicando impugnação objetiva de atos de órgãos e instituições da União Europeia.

\section{Direito à Boa Administração nas Ordens Constitucionais Portuguesa e Espanhola}

Na doutrina portuguesa a ideia de boa administração identificou-se, num primeiro momento, com o princípio da eficiência, no sentido de que Administração Pública deve atuar da melhor forma possível, incorporando em suas decisões princípios de gestão e de racionalidade econômico financeira, não possuindo aquela "[...] a faculdade de mal administrar, nem lhe é admissível uma postura de indiferença sobre o modo como prossegue o interesse público [...]", nas palavras de Otero (2016, p. 78).

Dentro de tal concepção, a vinculação da Administração Pública a essas pautas seria diversa daquela existente no tocante à lei, de modo que a violação ao princípio da boa administração uma "legalidade indireta", ainda conforme Otero (2016, p. 79). 
A Constituição da República Portuguesa de 1976, por sua vez, não consagra expressamente um direito fundamental à boa administração, muito embora diversas previsões sejam formas de sua concretização, como: a) a previsão de consecução pela Administração Pública do interesse público (artigo 266, 7, incisos 1 e 2), o que constitui maneira de assegurar a imparcialidade na sua atuação, tal como consta do artigo 41 da Carta de Direitos Fundamentais; b) o incentivo à desburocratização, à aproximação dos serviços da população e a busca de formas de descentralização e a desconcentração, além da racionalização de meios (artigo 267.1 e 5), coetânea com a previsão da razoável duração do processo, também constante do referido dispositivo normativo citado; c) as expressas previsões dos direitos do cidadão de ser informado, de acesso à informação, e a necessidade de motivação das decisões administrativas (artigo 268).

Tem-se, assim duas vertentes de compreensão do princípio da boa administração, sendo a primeira representada por objetivos e diretrizes da Administração Pública e a segunda, respaldada em posições especificas, como verdadeiro direito fundamental, atrai todo o regime que lhe e peculiar e que, na Constituição Portuguesa, no tocante aos direitos, liberdades e garantias, implica a aplicação direta e a vinculação das entidades públicas e privadas; a necessidade de as restrições serem feitas por meio de lei e nos casos expressamente previstos pela Constituição, limitando-se ao necessário para salvaguardar outros direitos e interesses constitucionalmente protegidos e a impossibilidade de as leis restritivas terem efeitos retroativos ou diminuírem o alcance e a extensão do conteúdo essencial dos preceitos constitucionais, tudo nos termos de seu artigo $18^{\circ}$.

Considerando-se, ainda, a natureza jusfundamental do direito à boa administração, a sua percepção como objetivos e diretrizes a serem cumpridos pela Administração Pública corresponde à sua dimensão objetiva, a qual compreende o valor que os direitos fundamentais assumem na ordem jurídica, como "[...] elementos fundamentais da ordem objetiva da coletividade [...]", segundo Hesse (1998, p. 228), trazendo importantes derivações, como a proteção às garantias institucionais, a eficácia horizontal (possibilidade de invocação nas relações privadas, e a afirmação 
dos deveres de proteção estatal, consoante destaca Vieira de Andrade (2001, p. 111).

Por sua vez, a violação de posição jusfundamental à boa administração acarreta consequências diversas do que a sua não observância como objetivo a ser cumprido pela Administração Pública.

A Constituição espanhola assim como a portuguesa, não contempla expressamente o direito fundamental à boa administração, muito embora do seu artigo 103.1 possam ser extraídos os "fundamentos normativos de uma boa administração", consoante destaca Ruiz (2011, p. 57), na medida em que tal preceito encerra diversos princípios que formatadoras daquela, como eficácia, hierarquia, descentralização, desconcentração, coordenação e legalidade administrativa.

Aponta ainda referido autor a importância do artigo 105, "a" e "c" que cuida da participação do cidadão na esfera administrativa por meio de um direito de audiência, diretamente ou por meio de organizações e associações, e do artigo 129, que atribui ao legislador a tarefa de estabelecer formas de participação dos cidadãos nas atividades dos organismos públicos naquilo que venha a afetar a qualidade de vida ou o bem-estar geral.

Importante aspecto sobre a funcionalidade do direito fundamental à boa administração, na ordem constitucional espanhola, seria a vinculação entre o interesse geral, a ser buscado pela Administração Pública, e a realização dos direitos fundamentais num Estado social e democrático de Direito, comprometido, por sua vez, com o implemento da melhoria de condições que assegurem a liberdade solidária das pessoas e dos grupos, consoante destaca Arana (2011, p. 99).

A doutrina, por sua vez, enuncia alguns signos de boa administração, destacando Baquer (2011, p. 52-53) os seguintes: a) a garantia da mais absoluta correção e neutralidade na contratação publica; b) a profissionalização da função pública e o respeito ao seu campo próprio de atuação, o qual não pode ser substituído pelos políticos, a quem cabe a alta direção e a fixação das políticas, sendo de todo indevida a "[...] conversão deles, por arte de magia, em especialistas nas mais árduas questões [...]"; d) a realização de concursos públicos em que se assegure a busca dos can- 
didatos mais qualificados, expressão da meritocracia, bem como a maior neutralidade possível de atuação; e) a firme concepção de que "dinheiro público é sagrado", demandando planejamento para que não sejam feitos gastos desnecessários; f) incidência de toda uma gama de controles, à disposição no ordenamento jurídico.

Pode-se também encontrar na doutrina entendimento no sentido de que o direito à boa administração seria simplesmente o direito de ser administrado da melhor maneira possível, não sendo permitido ao Estado administrar mal, até mesmo em razão dos fins para os quais existe, tal como o faz Pegoraro (2011, p. 36).

$\mathrm{Na}$ realidade, ainda conforme Pegoraro, (2011, p. 37) a fórmula "boa administração" na senda de outras fórmulas como freedom of speach, vão ter seu conteúdo preenchido pela jurisprudência, pela doutrina, pela legislação as quais vão realizando o que chama de "progressivas individualizações de situações jurídicas e ações".

Nada obstante, consoante assinalado anteriormente, a disposição do artigo 51 da Carta de Direitos Fundamentais da União Europeia permite aplicação expansiva dos direitos nela assegurados, de modo que não apenas quando se esteja diante de órgãos e organismos da União Europeia serão invocáveis as disposições daquela, ainda que a aplicação aos Estados membros ocorra apenas quando se aplique o Direito da União.

Conforme destaca Baquer (2011, p. 48), além de o ordenamento jurídico espanhol encontrar-se recheado de normas que são, de fato, Direito da União Europeia, como a Lei de Contratos do Setor Público, no caso, a Lei n. 30/2007, de 30 de outubro, e da imensa maioria das normas ambientais, o direito à boa administração quedaria perfeitamente encaixado no espaço do "procedimento administrativo comum", referido pelo artigo 149.1.18 a da Constituição.

No tocante à forma de proteção do direito à boa administração no sentido objetivo, convém destacar a importância da figura do Defensor del Pueblo, previsto no artigo 54 da Constituição espanhola, vinculada ao Parlamento e que possui como função supervisionar a atividade da Administração Pública para garantir a defesa dos direitos fundamentais e liberdades públicas do título I da Constituição 
Discute-se se a supervisão da atuação da Administração Pública pelo Defensor del Pueblo apenas poderia se dar a título de proteção dos direitos dos cidadãos ou se poderia ele agir em caso de má administração, ainda que não esteja em causa, imediatamente, a violação de direito subjetivo de um cidadão.

Nesse sentido, para Rodriguez (2011, p. 148-150), teria tal figura uma missão principal, que seria coadjuvar a defesa dos direitos dos cidadãos, e uma acessória, representada pela supervisão da atuação administrativa, embora entenda que não pode o mesmo transformar-se em um simples supervisor da legalidade sem que tenha por referência uma situação subjetiva do cidadão. Suas competências, por sua vez, encontram-se detalhadas na respectiva Lei Orgânica, especificamente em seu artigo $9^{\circ}$.

Em síntese, a concepção de boa administração encontra-se presente nas ordens constitucionais portuguesa e espanhola, ainda que com significados e desdobramentos próprios, contando com caminhos institucionais para assegurar sua observância, certamente variados em função de se estar diante de perspectiva objetiva ou subjetiva.

\section{O Direito à Boa Administração na Ordem Constitucional Brasileira}

O texto da Constituição Federal de 1988 não contempla expressamente o "direito à boa administração", expressão talhada no contexto da Carta Europeia de Direitos Fundamentais, obviamente não extensível a países que não façam parte da União Europeia.

Nada obstante, todas as posições asseguradas no artigo 41 da Carta de Direitos Fundamentais da União Europeia encontram-se expressamente previstas na realidade constitucional brasileira, recebendo, ainda, significativos aportes da legislação infraconstitucional, além de ser possível destacar a compreensão do direito à boa administração como "elemento fundamental da ordem objetiva da coletividade", assomando como a dimensão objetiva de referido direito. 
Partindo do texto constitucional, em seu artigo $5^{\circ}$, incisos LIV e LV, tem-se assegurado o contraditório e ampla defesa, bem como o devido processo legal e que corresponde ao item 1 do artigo 41 da mencionada carta, ou seja, ao direito do cidadão ser ouvido antes da adoção de qualquer medida pela Administração Pública que lhe seja desfavorável.

Semelhante concepção já se encontra devidamente sedimentada na jurisprudência pátria, sendo inúmeros os precedentes ${ }^{3}$ relativamente à necessidade de observância do devido processo legal na esfera administrativa não apenas para a imposição de penalidades, mas para todas as situações restritivas de direitos ou que venham a eliminar posições favoráveis.

$\mathrm{O}$ direito de acesso aos expedientes e documentos encontra-se assegurado no artigo $5^{\circ}$, XXXIII que assegura o direito a todos de "[...] receber dos órgãos públicos informações de seu interesse particular, ou de interesse coletivo ou geral, ressalvadas aquelas cujo sigilo seja imprescindível à segurança da sociedade e do Estado".

A entrada em vigor da Lei n. 12.527, de 18 de novembro de 2011, por sua vez, trouxe importante disciplinamento sobre aspectos como a definição do conteúdo do acesso à informação (artigo $7^{\circ}$ ); a previsão dos deveres dos órgãos públicos (artigo $8^{\circ}$ ); o procedimento de acesso à informação (artigo 10); os recursos cabíveis em caso de negativa (artigo

${ }^{3}$ Em matéria do Poder Disciplinar da Administração Pública, por exemplo, o controle jurisdicional dirige-se, precipuamente, à verificação da observância de tais garantias, como ressalta o Superior Tribunal de Justiça: "É firme a jurisprudência desta Corte no sentido de que "[...] o controle do Poder Judiciário no tocante aos processos administrativos disciplinares restringe-se ao exame do efetivo respeito aos princípios do contraditório, da ampla defesa e do devido processo legal". (Ag int no RMS 49202/ PR -2015/0218887-4, DJE 09/05/2017. Colhendo ainda exemplos da jurisprudência do STJ, há também necessidade de observância do devido processo legal para a exclusão de militar por deserção ( RMS 52678/GO- 2016/0321618-8, DJE 20/04/2017; para reconhecimento de falta grave praticada por detento no âmbito de estabelecimento prisional ( HC 381251/MG- 2016/0319614-2, DJE 14/03/2017; para licenciamento de militar, a bem da disciplina, sendo suficiente sindicância com ampla defesa e contraditório (REsp 165.1677/PR- 2016/0331696-8, DJE 24/04/2017; para suspensão ou cancelamento de benefício previdenciário, ainda que haja suspeita de fraude na sua concessão (AgInt no AREsp 916717/ES- 2016/0120866-7, DJE 20/09/2016); para recusa de registro de aposentadoria pelo Tribunal de Contas da União. 
15); as restrições ao acesso à informação, com a definição das situações de imprescindibilidade do sigilo, como referido pela Constituição (artigo 23); a definição dos prazos máximos de restrição (artigo 24); os procedimentos de classificação, reclassificação e desclassificação dos sigilos (artigos 27, 28 e 29); o tratamento das informações pessoais (artigo 31).

Já o dever de motivação das decisões possui também fundamento constitucional, em decorrência, primeiramente, da formula Estado Democrático de Direito, adotada pelo artigo $1^{\circ}$ da CF como caracterizadora da República Federativa do Brasil, de modo que dos princípios republicano, democrático e do Estado de Direito decorrem importantes desdobramentos, como a necessidade de prestação de contas por parte do agente público, o qual precisa demonstrar que agiu não de acordo com sua vontade, mas sim de acordo com o Direito, permitindo, ainda, a fiscalização de sua atuação, a qual deve conter abertura para incorporar visões e influencias dos cidadãos, dentro, certamente, de um procedimento administrativo, consoante explica Martins (2008, p. 236-237) ${ }^{4}$.

Além disso, o artigo 93, X da CF, que exige motivação das decisões administrativas dos Tribunais (Poder Judiciário) deve ser compreendido, na realidade, como atinente à função administrativa, independentemente do Poder que esteja a exercê-la, como decorrência do princípio hermenêutico da unidade da Constituição, em virtude do qual devem ser consideradas a conexão e interdependência de suas normas, de modo não ser possível olhar apenas para uma delas, evitando-se, assim, contradições, de acordo com a doutrina de Hesse (1998, p. 65).

Por sua vez, o artigo 50 da Lei n. 9.784/1999 enuncia uma série de situações em que a Administração Pública necessita motivar seus atos, nomeadamente aquelas em que há negação, restrição de direitos, imposi-

$4 \mathrm{O}$ autor realiza, na senda das teorias desenvolvidas pela doutrina portuguesa (antiformalista, funcionalista ou finalista e substancialista) importante estudo sobre a natureza do vício de ausência de motivação dos atos administrativos, vale dizer, se de forma ou conteúdo. Segundo ele, a ausência de motivação ou a sua insuficiência acarretam a invalidade do ato, impondo o dever de corrigir o vício, nem sempre exigindo, todavia, a invalidação do ato. $\mathrm{O}$ vício de motivação geraria a obrigatoriedade de invalidação do ato apenas na hipótese de, num processo administrativo, os atos conclusivos não terem analisado os elementos probatórios dele constantes. (2011, p. 249 e ss.). 
ção de deveres, encargos e sanções, decisão em processos de concurso ou seleção pública, decisão sobre invalidação, convalidação e revogação de atos administrativos.

No tocante à indenização pelos danos causados pelo Estado ao cidadão ou à pessoa jurídica, igualmente a ordem constitucional brasileira estabelece em seu artigo $37, \S 6^{\circ}$, a responsabilidade objetiva das pessoas jurídicas de direito público e das de direito privado prestadoras de serviço público.

O tema da responsabilidade civil do Estado na jurisprudência brasileira encontra largo desenvolvimento, reconhecendo-se a obrigação do Estado de indenizar, sob o regime da responsabilidade objetiva, tanto por comportamentos comissivos quanto omissivos ${ }^{5}$, predominantemente em razão de atos administrativos ou operações materiais da Administração Pública e, de forma mais restrita, no tocante aos atos judiciais e legislativos ${ }^{6}$.

Além das apontadas correspondências entre a Carta de Direitos Fundamentais da União Europeia e a Constituição brasileira quanto ao direito à boa administração, sob o aspecto subjetivo cumpre destacar, ainda considerando tal realidade, entre os elementos apontados pela doutrina espanhola, outros dignos de nota, como: o direito à participação do usuário na Administração Pública, nos termos do artigo 37, § $3^{\circ}$, da $\mathrm{CF}^{7}$, quer por meio de reclamações sobre a prestação de serviços públicos e sua avaliação periódica, quer mediante a representação contra abuso de poder ou seu exercício negligente; o direito a procedimentos tanto de con-

\footnotetext{
${ }^{5}$ No sentido de a regra da responsabilidade objetiva do Estado aplicar-se tanto a atos comissivos quanto omissivos ver as seguintes decisões do STF: ARE 888610/AgR/ PB, Dje 01/07/2015; ARE 897890/PR, DJe 19/10/2015; ARE 956285AgR/CE, Dje 24/08/2016.

${ }^{6}$ Em se tratando de atos judiciais a responsabilidade civil do Estado apenas é reconhecida nas hipóteses previstas em lei, consoante reafirmou o STF no julgamento do ARE 833909/ AgR/SC, Dje 19/05/2017. Já a responsabilidade por atos legislativos pode eclodir no caso de leis inconstitucionais (RE 163.039, DJe 07/06/1993), bem como no caso de leis de efeitos concretos, desde que presentes o dano e o nexo de causalidade. Sobre o tema ver Furtado (2010, p. 1.076/1.077).

${ }^{7} \mathrm{O}$ qual remete para a lei a regulamentação do tema.
} 
tratação pública ${ }^{8}$ quanto de concursos públicos absolutamente hígidos e transparentes; a garantia da meritocracia do serviço público ${ }^{9}$, podendo-se também vislumbrar, no tocante a todos eles, vertentes objetivas, consoante adiante tratado ${ }^{10}$.

Do panorama acima, verifica-se, no que diz respeito às posições garantísticas dos cidadãos concretizadoras do direito fundamental à boa administração, a ordem jurídica brasileira encontra-se alinhada às pautas mais atuais constantes de uma norma que representa marco sobre o tema, como o e a Carta de Direitos Fundamentais da União Europeia.

Passa-se, agora, a apreciar a possibilidade de reconhecer a presença de vertente objetiva do direito fundamental à boa administração e suas consequências e possíveis formas de seu controle.

Parte-se, primeiramente, da própria principiologia do artigo $37 \mathrm{da}$ CF que contempla, entre as pautas vinculativas da Administração Pública, a legalidade (atuação dentro de um Estado de Direito), a impessoalidade administrativa, compreendida como imparcialidade, a qual exige a consideração objetiva do interesse público ou, nas exatas palavras de Vieira de

${ }^{8} \mathrm{O}$ artigo 37 , XXI da $\mathrm{CF}$, ao tratar da licitação como procedimento normalmente antecedente aos contratos administrativos, prevê a necessidade de se assegurar "igualdade de condições a todos os concorrentes, com cláusulas que estabeleçam obrigações de pagamento, mantidas as condições efetivas da proposta, nos termos da lei, o qual somente permitirá as exigências de qualificação técnica e econômica indispensáveis à garantia do cumprimento das obrigações".

${ }^{9}$ Nesse sentido, tanto a forma regular de ingresso no serviço público, deve ser o concurso público, quando eles devem ser elaborados "de acordo com a natureza e a complexidade do cargo ou emprego" (CF, artigo 37, II), de modo que os cargos em comissão e as funções de confiança para os casos de "direção, chefia e assessoramento", de acordo com o artigo 37, $\mathrm{V}$ da CF. No tocante á profissionalização, o $\S 2^{\circ}$ do artigo 39 trata da manutenção, pela União e pelos Estados, de "escolas de governo para a formação e o aperfeiçoamento dos servidores públicos, constituindo-se a participação nos cursos um dos requisitos para a promoção na carreira".

${ }^{10}$ A participação procedimental para construção de decisões administrativas, bem como o direito a licitações e a concursos que primem pela imparcialidade, moralidade e transparência são expressões do status ativus processualis, ou seja, o direito `a participação e ao procedimento acrescentado por Haberle aos clássicos status dos direitos fundamentais propostos por Jellinek, tal como descrito por Sarlet (2003, p.164). 
Andrade (1994, p. 224-225), a tomada de decisões "com base em critérios próprios, adequados ao cumprimento das suas funções especificas no quadro da atividade geral do Estado".

A seguir, destaca-se a moralidade, que possui como aspecto "pessoal funcional a probidade administrativa" (FIGUEIREDO, 2000, p. 22) e cuja violação configura improbidade administrativa (CF, artigo $37 \S 4^{\circ}$ ), condutas ora causadoras de dano ao erário ora ensejadoras de enriquecimento ilícito do agente público, ora gravemente violadoras dos princípio da Administração Pública, densificadas por sua vez, na Lei n. 8.429/1992; a publicidade, que exige transparência no exercício da função administrativa, assegurando o acesso a informações também de caráter geral, consoante anteriormente destacado, estabelecendo, ainda, as finalidades e restrições à propaganda governamental (artigo 37, $\S 1^{\circ}$ ), por fim, a eficiência, a exigir utilização racional dos recursos públicos, com seu adequado controle, o atingimento de metas, a busca pela qualidade.

Como realidades também objetivas do direito à boa administração pública, e tem-se consoante ressaltado anteriormente, a exigência de absoluta correção e transparência dos procedimentos licitatórios e de concursos públicos, cuja burla implica, inclusive em improbidade administrativa; a profissionalização no serviço público além de reforçado sistema de controle da gestão pública, a ser realizado tanto pela própria Administração Pública (controle interno) quanto externo (Poder Legislativo com auxílio do Tribunal de Contas e Poder Judiciário).

Como formas de controle do direito fundamental à boa administração faz-se importante identificar as situações que ensejam recurso ao Poder Judiciário daquelas outras que demandarão outras formas de conformação e controle.

\section{Do Controle da Boa Administração}

Passa-se, a seguir, a analisar as diversas instâncias passíveis de exercer controle sobre a observância do direito fundamental à boa administração. 


\subsection{Pela Administração Pública}

A primeira garantidora da observância do direito à boa administração, tanto no que diz respeito às posições subjetivas dos cidadãos quanto ao seu valor objetivo na ordem jurídica é a própria Administração Pública, cuja atuação encontra-se vinculada àquele.

Assim, dentro de seus controles internos, como invalidação e revogação de atos administrativos, homologação de concursos, licitações, além apuração de condutas que tenham deflagrado a responsabilidade extracontratual daquela aplicação de sanções administrativas tanto a servidores públicos quanto a cidadãos em geral a Administração Pública deve fazer valer as posições jusfundamentais concretizadoras do direito à boa administração, impondo consequências pelo seu não cumprimento.

Quanto ao segundo aspecto, cabendo a ela as decisões a respeito das múltiplas formas de realização do interesse público, tem-se que, na elaboração e implementação das políticas públicas, deve a Administração procurar realizar os valores da atuação dentro do Estado de Direito, imparcialidade, moralidade, transparência, relação adequada entre custo e benefício com atingimento de metas, condutas, que, por sua vez são aferíveis por meio dos processos de controle internos, de previsão constitucional (artigo 74) deflagrados tanto de oficio quanto por cidadão, partido político, sindicato, nos termos do artigo $74, \S 2^{\circ}$. Há, portanto, reforçado sistema para assegurar a realização, nas palavras de Freitas, (2012, p. 198) de um:

[...] direito fundamental à Administração Pública eficiente e eficaz, cumpridora de seus deveres, com transparência, sustentabilidade, motivação, proporcional, imparcial e respeito à participação social e à plena responsabilidade por suas condutas omissivas e comissivas $[\ldots]$.

\subsection{Pelos Tribunais de Contas}

Ao auxiliar o exercício do controle externo da Administração Pública a ser feito pelo Poder Legislativo, os Tribunais de Contas realizam, 
precipuamente, o controle da boa Administração em sentido objetivo, verificando tanto a observância da legalidade quanto da legitimidade e economicidades dos gastos públicos, possuindo específicas competências em relação a atos como controle de admissão de pessoal, concessão de reformas, aposentadorias e pensões, os quais ficam submetidos à sua homologação para quedarem-se definitivos (artigo 71, III); determinação de providências para sustação de vícios ou mesmo sustação de ato por uso indevido de recursos públicos (artigo 71, IX e X); comunicação ao Congresso Nacional sobre a necessidade de sustar contrato administrativo, também no caso de mau uso de verbas públicas (artigo 71, $\S 1^{\circ}$ ).

As competências do Tribunal de Contas em relação ao controle da boa administração vão além, portanto, do exame da legalidade, mas sem implicar, conforme pontua Martins (2011, p. 381), um juízo de mérito, próprio da Administração Pública, mas um juízo de juridicidade. Ou seja, enquanto órgão de controle, o Tribunal de Contas não pode substituir as escolhas feitas pelo administrador que estejam em consonância com quadro normativo que referenda sua atuação, e dentro do qual se encontra o princípio da eficiência.

\subsection{Pelo Poder Judiciário}

A violação das posições subjetivas decorrentes do direito à boa administração enseja ao seu titular o acesso à Justiça para garantir a sua observância pela Administração Pública, com a restauração de todos os danos que tenham sido causados pela sua não observância, cabendo chamar a atenção, atualmente, para a possibilidade de resolução dos conflitos pela via consensual, estimulada pela Lei n. 13.140, de 26 de junho de 2015, cujo capítulo II é dedicado à composição de conflitos em que for parte pessoa jurídica de direito público.

Já a violação do direito à boa administração em sua vertente objetiva acarretará tanto legitimidade diversa daquele que irá provocar o controle da Administração Pública quando os próprios mecanismos e instâncias para fazê-lo.

Com efeito, há situações em que a violação à boa administração, no seu aspecto objetivo, podem ser aferidas pelo Poder Judiciário e outras 
cuja apreciação escapa, se não totalmente ao seu raio de controle, de forma ao menos parcial, restringindo-se sobremaneira sua intensidade.

Como importantes instrumentos de provocação do Poder Judiciário para apreciar a "boa administração" na sua vertente objetiva, tem-se, na ordem jurídica brasileira, a Ação Popular contemplada no artigo $5^{\circ}$, LXXIII da $\mathrm{CF}^{11}$, destinada a "[...] anular ato lesivo ao patrimônio público ou de entidade que o Estado participe, à moralidade administrativa, ao meio ambiente e ao patrimônio histórico cultural"; a Ação Civil Pública, no que conectarem-se os signos da boa administração, acima tratados, com a proteção ao meio ambiente, a bens e direitos de valor artístico, estético, histórico, turístico e paisagístico, às ordens econômica e urbanística e ao patrimônio público e social, nos termos do artigo $1^{\circ}$, III, V,VI e VIII da Lei n. 7.347/85, e, por fim, a Lei da Improbidade Administrativa, que regulamenta o artigo $37, \S 4^{\circ}$, da $\mathrm{CF}$, e que, além de definir quais condutas, omissivas ou comissivas configuram improbidade administrativa, estabelece "[...] as sanções aplicáveis aos agentes públicos nos casos de enriquecimento ilícito no exercício de mandato, cargo, emprego ou função na administração pública direta, indireta ou fundacional."

Enquanto que a legitimidade para propositura da Ação Popular cabe ao cidadão, no caso da Ação Civil Pública é ela atribuída, nos termos do artigo $5^{\circ}$ da Lei n. 7.345/87, ao Ministério Público, à Defensoria Pública, União, Estados, Municípios e Distrito Federal, além de suas entidades da Administração Indireta, associações que tenham entre seus objetivos institucionais a defesa dos bens e valores referidos pela diploma normativo em questão, cabendo, por fim, a propositura da Ação de Improbidade Administrativa, ao Ministério Público ou "à pessoa jurídica interessada", de acordo com o artigo 17 da Lei n. 8.429/1992.

As vias de sindicabilidade, pelo Poder Judiciário, da boa administração podem conduzir a importantes debates sobre a atuação da Administração Pública, muito embora, no âmbito judicial, dadas as finalidades e a própria configuração do processo, acabe por haver limitações quanto à realização de avaliações mais apropriadas de todos os fatores, variáveis e intersecções de ordem administrativa, econômica, política, ambiental,

${ }^{11}$ Cuja disciplina encontra-se na Lei n. 4.717/65. 
urbanística, social envolvidos nas mais diversas questões, com os respectivos conflitos delas originários. Assim, as decisões judiciais sobre a boa administração precisam procurar ater-se aos seus legítimos espaços, sem tentar dar respostas aquilo que seja próprio do sistema político, e não do jurisdicional.

Tais aspectos demonstram as dificuldades do tratamento, pelo Poder Judiciário de escolhas que cabem, precipuamente ao administrador, de modo que, no tocante, por exemplo, às políticas públicas, o controle jurisdicional embora admitido, não pode se afastar "[...] da análise formal dos limites desses parâmetros que privilegie a opção democrática das escolhas feitas pelo legislador e pela Administração Pública [...]”, tal como decidiu o Supremo Tribunal Federal, no Recurso Extraordinário n. 677.189/SP, com repercussão geral.

Não se está a sustentar, de forma alguma, a impossibilidade de aferição das escolhas feitas pelo administrador quer na formulação e implementação das políticas públicas, quer no exercício da competência discricionária, mas apenas pontuando as dificuldades e as limitações do controle jurisdicional, o que deve conduzir ao aprimoramento de outras formas de verificação da observância dos postulados da boa administração.

\subsection{O Controle Social}

As limitações do controle jurisdicional sobre a boa administração, bem como a necessidade de trazer, ao âmbito dos controles administrativo e daquele exercido com o auxílio do Tribunal de Contas, uma abertura à sociedade, como manifestação do princípio democrático devem levar ao fortalecimento de outras instâncias, como o controle social sobre a Administração Pública.

Com efeito, a própria Constituição, consoante destacado anteriormente, consagra em seu artigo $37, \S 3^{\circ}$, a possibilidade de participação do cidadão na formação das decisões administrativas, o que leva tanto à valorização do iter daquelas, com a devida abertura procedimental para a incorporação das contribuições da sociedade, quanto corrobora para o fortalecimento da nova vertente da atuação administrativa, direcionada à busca de consensualidade. 
Por tais razões, além de uma tendência de acrescida procedimentalização da atividade administrativa, sendo ainda necessário explorar todas as virtualidades do procedimento e da participação da sociedade, conforme pontua Netto (2012, p. 218), a tentativa de construção de consensos contribui sobremaneira para a produção de decisões com maior grau de aceitação e legitimidade.

O fortalecimento das instâncias de participação da sociedade na formação das decisões administrativas possibilita, por sua vez, que o controle da boa administração, no seu aspecto objetivo, seja, além de realizado de forma prévia, incidente sobre aspectos que estão para além da juridicidade e que não podem ser fiscalizados quer pelo Poder Judiciário, quer pelo Tribunal de Contas.

Por meio, então, de referidas vias, a construção do mérito administrativo pode ser feita não de forma unitária e unilateral, mas participativa e pluralista, rendendo ensejo à concretização dos valores representativos da boa administração, como legalidade, imparcialidade, transparência, eficiência.

A título de exemplos, podem ser citados, a criação, pela Lei n. 8.142/90, dos Conselhos e Conferências de Saúde no âmbito do Sistema Único, cujo objetivo foi o de assegurar espaços de participação dos segmentos representativos do SUS, com caráter permanente e capacidade deliberativa, muito embora diversas vicissitudes tenham surgido ao longo de referida experiência consoante destaca Guizardi (2012, p. 584-585), bem como a previsão, na Lei n. 12.401/2011, de que a aprovação dos Protocolos Clínicos e Diretrizes Terapêuticas no âmbito do Ministério da Saúde seja necessariamente precedida de Consulta Pública a respeito do relatório elaborado pela Comissão Nacional de Incorporação de Tecnologias (CONITEC), nos termos do artigo 19-R, III daquela lei.

Importante mencionar também, a nova Lei n. 13.303, de 30/06/2016 que dispõe sobre o estatuto jurídico da empresa pública, da sociedade de economia mista e de suas subsidiarias, no âmbito da União dos Estados, do Distrito Federal e dos Municípios, no âmbito da qual se encontra tópico (Capítulo III) dedicado físcalização de tais empresas pelo Estado e pela Sociedade. 
Entre as disposições que mencionado capitulo encerra, além de uma diretriz geral de transparência a ser observada por parte de tais empresas, como a divulgação, por meio eletrônico, de informações sobre execução de seus contratos e orçamento (artigo 88), com a ressalva das informações referentes a operações de perfil estratégico (artigo $88, \S 1^{\circ}$ ), não oponíveis aos órgãos de controle, há a previsão da legitimidade do cidadão para impugnar edital de licitação (artigo 87, $\S 1^{\circ}$ ), bem como de representar, perante o Tribunal de Contas e os sistemas de controle interno sobre irregularidades concernentes à aplicação da Lei n. 13.303/2016.

Os exemplos acima trazidos certamente corroboram para a concretização da boa administração, devendo ser desenvolvidos também outros, dentro de uma mesma linha participativa.

Em suma, assim como nas realidades de Espanha e Portugal, também na realidade brasileira há de se distinguir as formas e as instancias de realização do controle da boa administração, tendo em vista a diversidade de espectros que ela assume, a demandar filtros que lhes sejam adequados.

\section{Conclusão}

O reconhecimento do direito fundamental à boa administração pela Carta de Direitos Fundamentais da União Europeia veio a implicar a fixação, em seu artigo 41, de uma pauta de posições garantísticas mínimas dos cidadão da União Europeia em relação aos seus órgãos, compreendendo aquelas, por sua vez, o direito de manifestação, antes de qualquer medida ou decisão desfavorável, o direito ao acesso a expedientes e documentos que se encontrem em poder dos órgãos comunitários, o direito à reparação por danos causados por esses últimos e, por fim, o direito a dirigir-se aos órgãos da União Europeia na linguagem de seu Estado-membro. Referida previsão possui vocação expansiva e interpretativa para os Estados membros da União Europeia, com importante influencia em seus ordenamentos constitucionais.

A Constituição Portuguesa não prevê, expressamente, o direito fundamental à boa administração, embora diversos dispositivos o con- 
cretizem, como a previsão de consecução pela Administração Pública do interesse público (artigo 266, 1 e 2), o incentivo à desburocratização, à aproximação dos serviços da população e a busca de formas de descentralização e a desconcentração, além da racionalização de meios (artigo $267,5)$, as expressas previsões dos direitos do cidadão de ser informado, de acesso à informação, e a necessidade de motivação das decisões administrativas (artigo 268). Cabe chamar a atenção, também para a identificação, feita pela doutrina, do direito à boa administração com o princípio da eficiência.

$\mathrm{Na}$ Constituição espanhola, a concretização do direito à boa administração encontra-se no artigo 103, I (previsão de legalidade, eficácia, descentralização, desconcentração), e nos artigos 105 e 129, consagradores da participação do cidadão na esfera administrativa, diretamente ou mediante associações, apontando ainda a doutrina outras práticas que lhes são coetâneas, como a profissionalização da função pública, a incidência de controles sobre Administração Pública, a correção nas contratações, o zelo com os recursos públicos.

Tanto no âmbito da Carta de Direitos Fundamentais quanto no das ordens constitucionais portuguesa e espanhola distinguem-se o controle do direito fundamental à boa administração na vertente subjetiva e na objetiva ensejador, no primeiro caso, da atuação do Poder Judiciário, e, no segundo, de outras instituições, como o Provedor de Justiça da União, o Tribunal de Contas e o Defensor do Povo.

$\mathrm{Na}$ ordem constitucional brasileira faz-se possível identificar o direito fundamental à boa administração tanto no aspecto subjetivo pois, encontram-se asseguradas todas as posições garantísticas perante o Estado como devido processo legal, contraditório e ampla defesa (artigo $5^{\circ}$, LIV e LV), direito à informação (CF, artigo 5, XXXIII), reconhecimento da responsabilidade civil do Estado (CF, artigo 37§6) e participação dos usuários na Administração Pública (CF, artigo 37, §3), com importantes desdobramentos legais, como a Lei do Processo Administrativo (Lei n. 9.784/99) e Lei de Acesso à Informação (Lei n. 12.527/2011), quanto no objetivo, tendo em vista a principiologia do artigo 37 caput (legalidade, moralidade, impessoalidade, publicidade, eficiência), exigência de abso- 
luta correção e transparência dos procedimentos licitatórios e de concursos públicos, a profíssionalização no serviço público além de reforçado sistema de controle da gestão pública.

Quanto às formas de controle, também se distinguem o da vertente subjetiva e o da objetiva do direito fundamental à boa administração. No primeiro caso, cabe tanto à própria Administração, no exercício de seus controles quanto ao Poder Judiciário e, no segundo, além dos controles administrativos internos e da atuação judicial via instrumentos como a Ação Popular (Lei n. 4.717/65, da Ação Civil Pública (Lei n. 7.347/85) e da Improbidade Administrativa (Lei n. 8.429/92), entram em cena o Tribunal de Contas, bem como o controle social, adquirindo o último crescente importância.

Por fim, o desenvolvimento do conceito de direito fundamental à boa administração no âmbito da ordem jurídica brasileira pode contribuir para valorizar e aprimorar práticas administrativas que sejam coetâneas com os valores e desideratos que dele emanam, reforçando as pautas que balizam a atuação dos agentes públicos.

\section{Referências}

ANDRADE, José Carlos Vieira de. A Imparcialidade da administração pública como princípio constitucional. Boletim da Faculdade de Direito, Coimbra, v. 50, p. 219-246, 1994.

BAQUER, Lorenzo Martin-Retortillo. De los derechos humanos al derecho a una buena administracion. In: RODRIGUEZ, Carmen Maria Avila; RODRIGUEZ, Francisco Gutierrez. EI derecho a una buena administracion y la ética publica. Valencia: Tirant lo blanch, 2011. p. 43-54.

CANOTILHO, Joaquim Jose Gomes. Compreensão Jurídico-Política da Carta. In: GORJÃO-HENRIQUES, Miguel et al. Carta de Direitos Fundamentais da União Europeia. Coimbra: Coimbra Editora, 2001. p.13-15. 
FIGUEIREDO, Marcelo. Probidade Administrativa. São Paulo: Malheiros, 2000.

GUIZARDI, Francini Lube. Direito à Saúde e a Participação Política no SUS: cenários, dispositivos e obstáculos. In: ASENSI, Felipe Dutra; PINHEIRO, Roseni. Direito Sanitário. Rio de Janeiro: Campus Jurídico, 2012. p. 583-596.

FREITAS, Juarez. As políticas públicas e o direito fundamental à boa administração. Nomos, Fortaleza, v. 35, n. 1, p. 195-217, 2015.

HESSE, Konrad. Elementos de direito constitucional da República Federal da Alemanha. Porto Alegre: Sérgio Antônio Fabris Editor, 1998. MOURA RAMOS, Rui Manuel. A Carta dos Direitos Fundamentais da União Europeia -Alguns Aspectos. In: GORJÃO-HENRIQUES, Miguel et al. Carta de Direitos Fundamentais da União Europeia. Coimbra: Coimbra Editora, 2001. p. 53-57.

MUNOZ, Jaime Rodriguez-Arana. El derecho fundamental a la buena administracion de instituciones publicas y el derecho administrativo. In: RODRIGUEZ, Carmen Maria Avila; RODRIGUEZ, Francisco Gutierrez. EI derecho a una buena administracion y la ética publica. Valencia: Tirant lo blanch, 2011. p. 77-105.

NETTO, Luísa Cristina Pinto. Procedimentalização e ParticipaçãoImposições jusfundamentais à atividade administrativa. In: NETTO, Luísa Cristina Pinto; BITENCOURT NETO, Eurico. Direito Administrativo e Direitos Fundamentais: diálogos necessários. Belo Horizonte: Editora Fórum, 2012. p. 215-242.

OTERO, Paulo. Manual de Direito Administrativo. Coimbra: Almedina.

PEGORARO, Lucio. Existe un derecho a la buena administracion? In: RODRIGUEZ, Carmen Maria Avila; RODRIGUEZ, Francisco Gutierrez; RODRIGUEZ. EI derecho a una buena administracion y la ética publica. Valencia: Tirant lo blanch, 2011. p. 17-41.

RODRIGUEZ, Carmen Maria Avila. La Buena Administracion. ¿Objeto de proteccion o critério de superivision de la actividad administrativa 
para la instituciones de los defensores del Pueblo. In: RODRIGUEZ, Carmen Maria Avila; RODRIGUEZ, Francisco Gutierrez. EI derecho a una buena administracion y la ética publica. Valencia: Tirant lo blanch, 2011. p. 131-177.

RUIZ, Gerardo Ruiz-Rico. El Derecho a una buena administracion. Dimensiones Constitucional y Estatutaria. In: RODRIGUEZ, Carmen Maria Avila; RODRIGUEZ, Francisco Gutierrez; EI derecho a una buena administracion y la ética publica. Valencia: Tirant lo blanch, 2011. p. 55-75.

SARLET, Ingo Wolfgang. A Eficácia dos Direitos Fundamentais. Porto Alegre: Livrariado Advogado, 2003.

WEBER, Albrecht. La Carta de los Derechos Fundamentales de la Union Europeia. Revista Espanola de Derecho Constitucional, Madrid, n. 64, p. 74-97, 2002.

VIEIRA DE ANDRADE, José Carlos. A Carta Europeia dos Direitos Fundamentais. In: GORJÃO-HENRIQUES, Miguel et al. Carta de Direitos Fundamentais da União Europeia. Coimbra: Coimbra Editora, 2001. p. 83-88.

Clarissa Sampaio Silva é professora na Universidade de Fortaleza. E-mail:sampaioclarissa@hotmail.com

Endereço profissional: Universidade de Fortaleza, Centro de Ciências Jurídicas (CCJ). Av. Washington Soares, n. 1.321, bloco K, Edson Queiroz, Fortaleza, CE. CEP: 60811-341. 